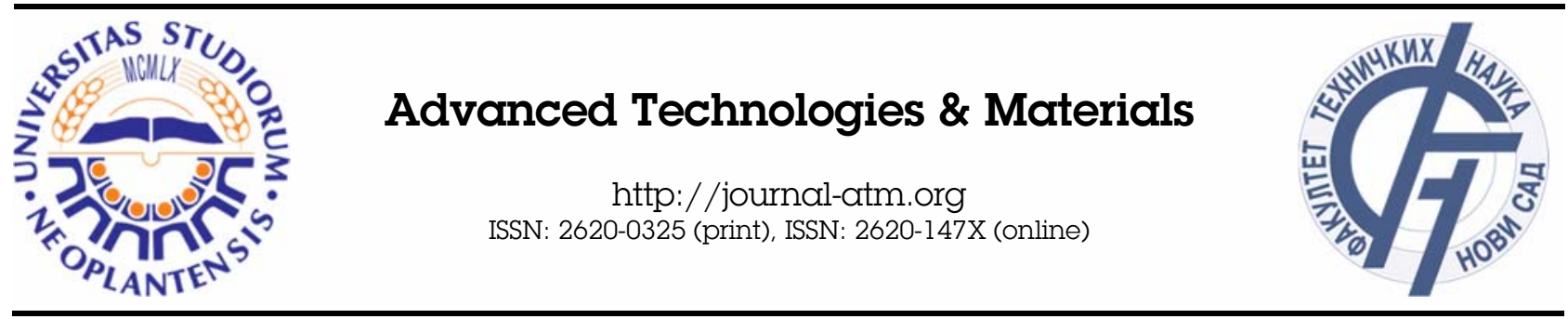

Original article

\title{
Comparative studies on the microstructure and corrosion behaviour of forged and SLM processed 316L stcinless steel
}

\author{
Dino Woelk, Norbert Kazamer, ${ }^{*}$ Gabriela Mărginean \\ Westphalian University of Applied Sciences, Neidenburger Str. 43, 45897, Gelsenkirchen, Germany
}

\begin{abstract}
The corrosion behaviour of forged and SLM (Selective Laser Melting) processed 316L samples was investigated in a 3.5\% $\mathrm{NaCl}$ solution at neutral and light acidic $\mathrm{pH}$. The influence of the oxygen concentration in the testing solution on the corrosion resistance of the alloy was also proved.

This made it possible to qualitatively evaluate the influence of the additive manufacturing process on the microstructure of the 316L alloy in comparison to that of the forged steel. Therefore, the logarithmic polarisation curves generated during the electrochemical investigations were compared, especially in respect to the corrosion potential respectively corrosion current density. The results showed that the corrosion resistance of the 3D-printed samples was inferior to that of the forged $316 \mathrm{~L}$. Instead of the pitting corrosion that often appears during exposure of the forged material to chloride containing media, the SLM processed material exhibited rather an extensive surface attack. The microscopic examination of the samples revealed large differences in porosity between the microstructures obtained by means of the two manufacturing methods, whereby the $3 D$-printed samples exhibited a larger number of voids.
\end{abstract}

Key words: selective laser melting, 316L, corrosion behaviour;

\section{$1 . \quad$ INTRODUCTION}

Selective laser melting (SLM) is one of the well-known additive manufacturing processes. This technology can generate complex geometries directly from metallic powders in inert atmospheres. A great advantage is that a CAD model can be read directly into the program of the 3D-printer [1,2]. Furthermore, the material loss of SLM is considerably lower compared to other classical fabrication techniques. The process is widely used in aerospace, railroad industry and for small batch production as well as for single part production. However, conventional procedures (such as casting) show advantages concerning lower production time and costs in comparison to SLM in the field of series production [3-6]. During the printing process the powder is locally melted by laser beam. The resulting high cooling rate causes dendritic solidification structure with different morphologies, depending on the powder particle diameter, which can show an improvement of the yield strength [7-9]. Furthermore, increased porosity often appears in SLM-produced objects compared to conventionally produced workpieces. The voids allow the medium to penetrate more quickly into deeper regions of the material, which again increases the risk of corrosion $[10,11]$. The corrosion resistance can also be influenced by the laser power and scanning speed $[12,13]$.

There are a variety of materials, which are widely used for industrial applications, for example, 316L stainless steel. This material is distinguished by various positive properties, especially in respect to a good corrosion resistance in chloride containing solutions [14]. Moreover, this material exhibits good mechanical strength and deformation behaviour $[15,16]$. Due to its biocompatibility, $316 \mathrm{~L}$ is often used for implants, as the material has no negative impact on health or the environment [17]. The corrosion properties of metallic materials are particularly important for their application, as the damage of components in service can often be attributed to corrosion. 316L forms a dense and adherent oxide layer (passive layer) that protects the substrate, hence the wide industrial application [18,19]. The present susceptibility of chloride induced pitting corrosion is a particular challenge, as it appears more frequently in materials with imperfections and irregularities. The SLM

*Corresponding author's.e-mail: norbert.kazamer@w-hs.de

Published by the University of Novi Sad, Faculty of Technical Sciences, Novi Sad, Serbia.

This is an open access article distributed under the CC BY-NC-ND 4.0 terms and conditions 
workpieces more often show these unwanted effects, whereby the pitting corrosion finds the access [20-22]. Due to the diverse applications of $316 \mathrm{~L}$, research activities are always being carried out to find ways of improving its properties. Other researchers reported about 3D printed samples made of a composite material $(316 \mathrm{~L}$ and glass powder). The glass content led to a reduction in the weight of the whole composite. Moreover, glass powder is a byproduct, which is thus being recycled [23].

This experimental work compares the corrosion behaviour of SLM produced 316L samples with that of forged 316L. The electrochemical experiments were done in $3.5 \% \mathrm{NaCl}$ solution (as produced and deaerated with $\mathrm{N}_{2}$ ) at different $\mathrm{pH}$ values (neutral and slightly acidic). The results obtained from the polarization curves were associated with the morphology of the $361 \mathrm{~L}$ material in metallographic cross-section.

\section{METHODOLOGY}

\subsection{Materials and manufacturing}

A large technological implementation requires using widely employed materials. The $316 \mathrm{~L}$ reference forgedmaterial was compared with SLM generated samples, using a powder from the company Flame Spray Technology with a particle size in the range $15-45 \mu \mathrm{m}$. An SEM micrograph showing the morphology of the material and its chemical composition can be seen in Fig. 1 and Table 1.

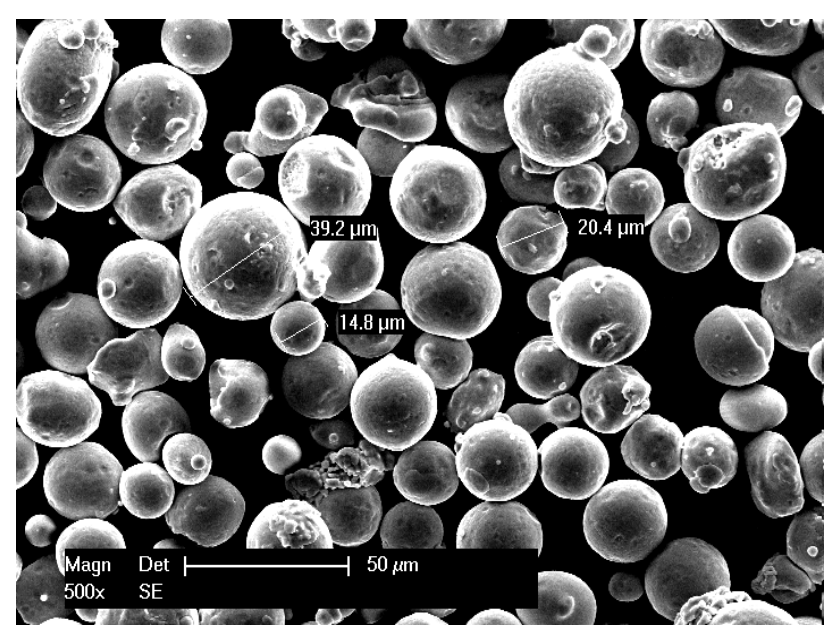

Fig.1 SEM micrograph of the used $316 \mathrm{~L}$ powder

Table 1 - Chemical composition of the powder according to its data sheet.

\begin{tabular}{lllllll}
\hline \multicolumn{7}{c}{ Nominal chemical composition (wt.\%) } \\
& $\mathbf{F e}$ & $\mathbf{C r}$ & $\mathbf{N i}$ & $\mathbf{M o}$ & $\mathrm{Si}$ & $\mathrm{C}$ \\
\hline 316L & Bal. & 16.0 & 10.0 & 2.0 & $<1.0$ & $<0.03$ \\
Powder & & - & - & - & & \\
& & 18.0 & 12.0 & 3.0 & & \\
\hline
\end{tabular}

At least three samples from each batch to ensure reproducibility were manufactured with a metal $3 \mathrm{D}$-printer Orlas Creator under a protective $\mathrm{N}_{2}$ atmosphere. The most important manufacturing parameters can be found in the Table 2.

Table 2 - Main printing parameters of the sample.

\begin{tabular}{cc}
\hline Parameter & Value \\
\hline Beam expander diameter & $40 \mu \mathrm{m}$ \\
Mark speed & $1750 \mathrm{~mm} \mathrm{~s}^{-1}$ \\
Angle & $45^{\circ}$ \\
Layer thickness & $45 \mu \mathrm{m}$ \\
Relative beam motion & Translation of the piece \\
Part build-up strategy & Bottom up \\
\hline
\end{tabular}

\subsection{Characterization}

The specimens used for electrochemical characterization were previously ground with a 80 grain size $\mathrm{SiC}$ paper to reach a common industrially employed roughness of $\mathrm{Ra} 1.6$ $\mu \mathrm{m}$. For the metallographic preparation of the samples in cross-section, the embedded specimens were ground up to 1200 grain size $\mathrm{SiC}$ paper and polished with $3 \mu \mathrm{m}$ diamond suspension.

The chemical composition of the forged and the SLM printed samples was determined by means of UV/VIS spectroscopy with a SpectroMAXx equipment.

The microstructural analysis was performed with a FEI EDX equipped Philips XL30 ESEM scanning electron microscope (SEM) at a $10 \mathrm{~mm}$ working distance and a cathode voltage of $25 \mathrm{kV}$. The porosity was calculated from the SEM micrographs with the ImageJ processing software.

The corrosion performance was investigated with a VoltaLab PGP201 Potentiostat/ Galvanostat in a conventional respectively deaerated 30 minutes with pure $\mathrm{N}_{2}, 3.5 \mathrm{wt} \% \mathrm{NaCl}$ solution. Additional measurements were done also at slight acidic $\mathrm{pH}$ (3.5), adjusting the $\mathrm{NaCl}$ solution with concentrated $\mathrm{HCl}$. The tests were performed at room temperature, using a three electrode-cell, under quasi stationary conditions, applying a scan rate of 0.16 $\mathrm{mV} \mathrm{s}^{-1}$. A Pt disc was defined as a counter electrode and a saturated calomel electrode (SCE) with a Luggin capillary as a reference electrode, respectively. The samples were scanned from $-600 \mathrm{mV}$ vs. SCE up to $1000 \mathrm{mV}$ vs. SCE and the corresponding corrosion potential ( $\left.\mathrm{E}_{\mathrm{corr}}\right)$, and current $\left(i_{\text {corr }}\right)$ were analysed.

\section{RESULTS AND DISCUSSIONS}

The morphology of the SLM processed $316 \mathrm{~L}$ material is depicted in Fig. 2. For a better three-dimensional presentation of the generated structure, cross-section samples were prepared in respect to planes, which are oriented along the $\mathrm{x}, \mathrm{y}$ and $\mathrm{z}$ direction.

The samples examined in the frame of this research work were not produced with optimal SLM parameters, since a large amount of voids respectively a certain amount of unmelted powder particles is present inside the structure. This observation confirms that the melting pool was unstable. The estimated porosity determined by image processing was in the range $15 \%$ up to $18 \%$, depending on 
the plane orientation. Very important for the corrosion behaviour of such structures, is that the present porosity is just in plane interconnected but not in the whole bulk.

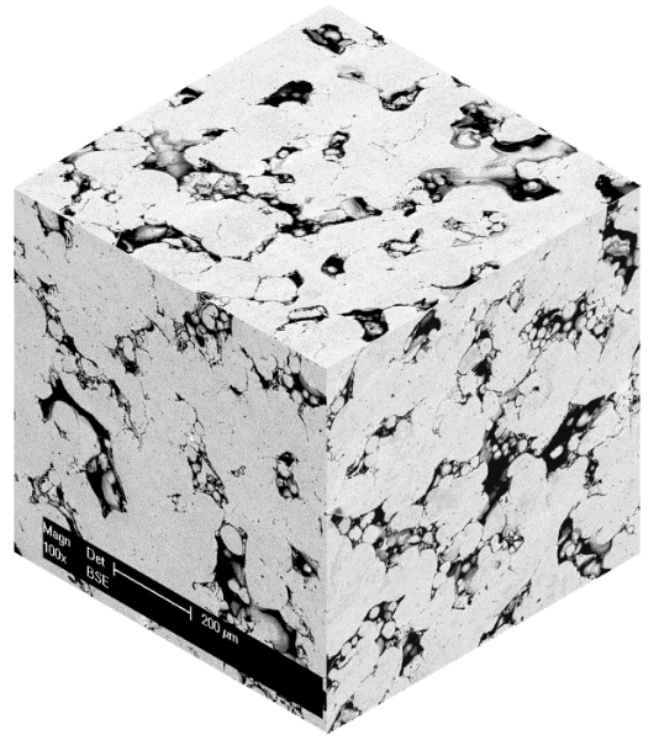

Fig.2 Three-dimensional representation of the SLM printed 316L material

The chemical composition of the investigated samples was determined in order to obtain information especially concerning the $\mathrm{Cr}$ and Mo content, which have a direct influence on the passivation behaviour of the stainless-steel surface. The contents of these elements are similar for both materials (forged and SLM printed, see Table 3). Furthermore, the forged alloy contains a slightly higher amount of $\mathrm{Ni}$, contributing to an improvement of the corrosion resistance.

Table 3-Average value of the chemical composition of the forged and SLM printed material determined of by UV spectroscopy.

\begin{tabular}{cccccccc}
\hline \multicolumn{7}{c}{ Nominal chemical composition (wt.\%) } \\
\hline & $\boldsymbol{C}$ & $\mathbf{S i}$ & $\boldsymbol{M n}$ & $\boldsymbol{C r}$ & $\mathbf{N i}$ & $\boldsymbol{M o}$ & $\boldsymbol{F e}$ \\
\hline Forged & 0.086 & 0.74 & 1.1 & 16.25 & 12.13 & 2.43 & 67 \\
\hline $\begin{array}{c}\text { SLM } \\
\text { Printed }\end{array}$ & 0.039 & 0.51 & 1.28 & 16.21 & 9.8 & 2.02 & 69.2 \\
\hline
\end{tabular}

Figure 3 shows the anodic polarization curves of forged 316L in all the mentioned testing conditions. During the corrosion attack of steel materials in in chloride containing aqueous media, the main anodic respectively cathodic electrochemical reactions are the iron oxidation and the oxygen reduction reaction (ORR), respectively.

Depending on the $\mathrm{pH}$ value of the testing solution, the ORR might generate hydroxyl ions $(\mathrm{pH}>7)$ or even just water $(\mathrm{pH}<7)$, concerning the following chemical reactions:

$$
\mathrm{O}_{2}+\mathrm{H}_{2} \mathrm{O}+4 e^{-} \rightarrow \mathrm{OH}^{-}
$$

or

$\mathrm{O}_{2}+4 \mathrm{H}^{+}+4 e^{-} \rightarrow 2 \mathrm{H}_{2} \mathrm{O}$
By comparing the course of the anodic branch, one may observe that the surface of the forged alloy is able to passivate over a wider potential range just in the oxygen containing solutions. Production of hydroxyl ions during the ORR supports the surface passivation process. This observation does not influence very much the $E_{\text {corr }}$ respectively the $\mathrm{i}_{\text {corr }}$. The sample exposed in the testing $\mathrm{NaCl}$ solution with $\mathrm{pH} 3.5$ exhibited higher values for $\mathrm{i}_{\text {corr }}$ due to the higher content in dissolved oxygen (DO).

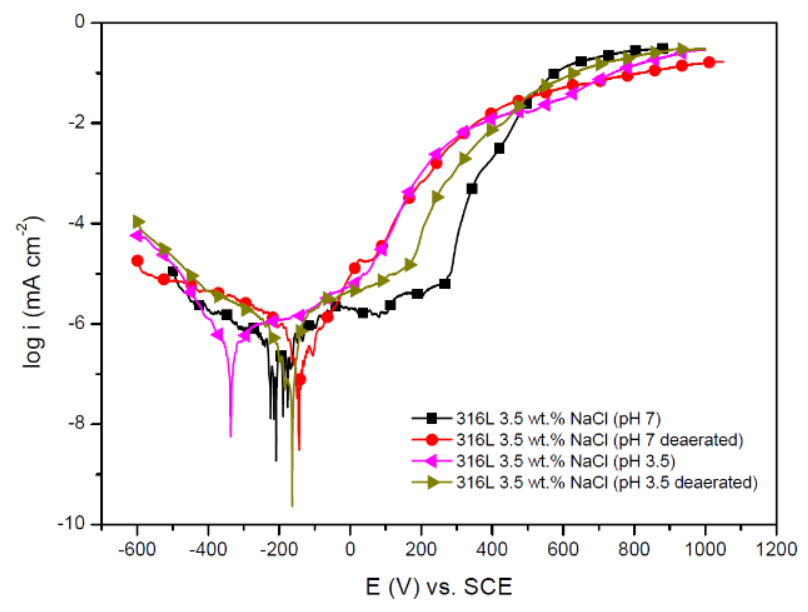

Fig.3 Three-dimensional representation of the SLM printed 316L material

The DO has a high solubility in 3,5 wt.\% $\mathrm{NaCl}$. Under these conditions, the ORR exhibited the lowest degree of inhibition (see the inclination of the cathodic branch, Figure 3) and the Ecorr was shifted to less nobler potentials. Hence, the DO is an electron acceptor (cathodic reaction), it accelerates the anodic metal dissolution.

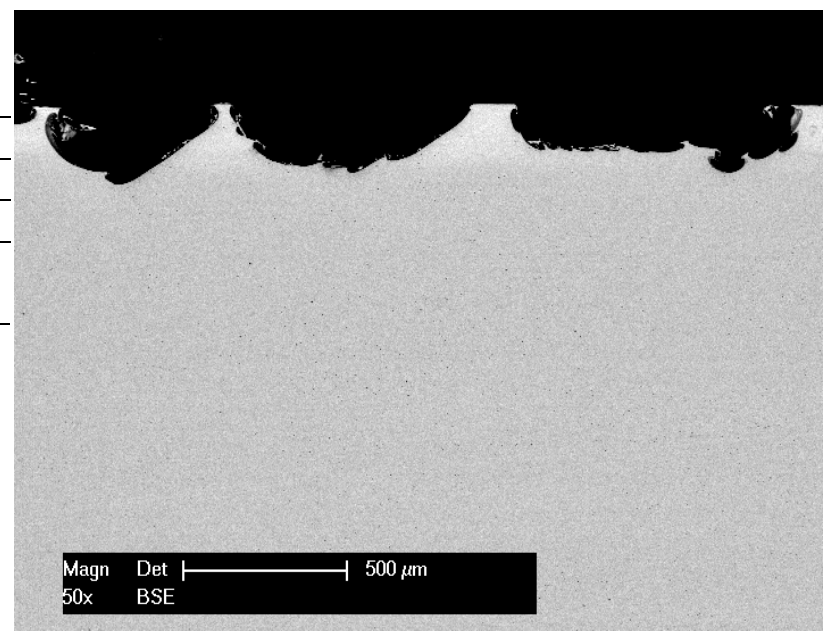

Fig.4Example of cross-section SEM micrograph of the corroded 326L forged material

The polarization curves of the investigated SLM printed 316L material show an additional trend concerning the influence of surface roughness and sample porosity on the corrosion behaviour, depending on $\mathrm{pH}$ value respectively on DO concentration.

The anodic branch of the samples tested in neutral chloride solution revealed weak passivation, independently from 
the DO concentration. These samples exhibit higher values for $\mathrm{i}_{\text {corr }}$ in comparison with that tested at lower $\mathrm{pH}$ values, which confirm a higher kinetic of the corrosion reaction. The presence of numerous voids in the sample structure leads to a higher specific surface which was exposed to corrosion, having a catalytic effect, especially on the oxidation reaction. The kinetics of the cathodic ORR controls not only the rate but also the extending of localized corrosion under these conditions.

A further aspect which should be considered is that the bottom of the existing voids is covered by a thin oxide layer, which was generated during the SLM processing of the material. A part of this oxide might be reduced during the ORR, especially under neutral conditions. Shifting the solution $\mathrm{pH}$ toward lower values will induce supplementary the chemical reaction (2), which will counterbalance the reaction (1). All these aspects produce a better stability of the generated passive film for the samples exposed to media lower $\mathrm{pH}$ values.

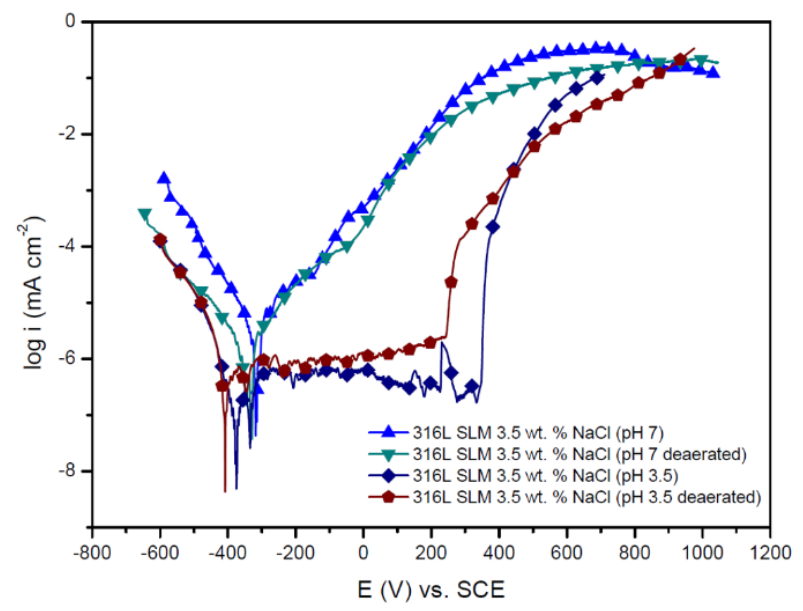

Fig.5Example of cross-section SEM micrograph of the corroded 316L forged material

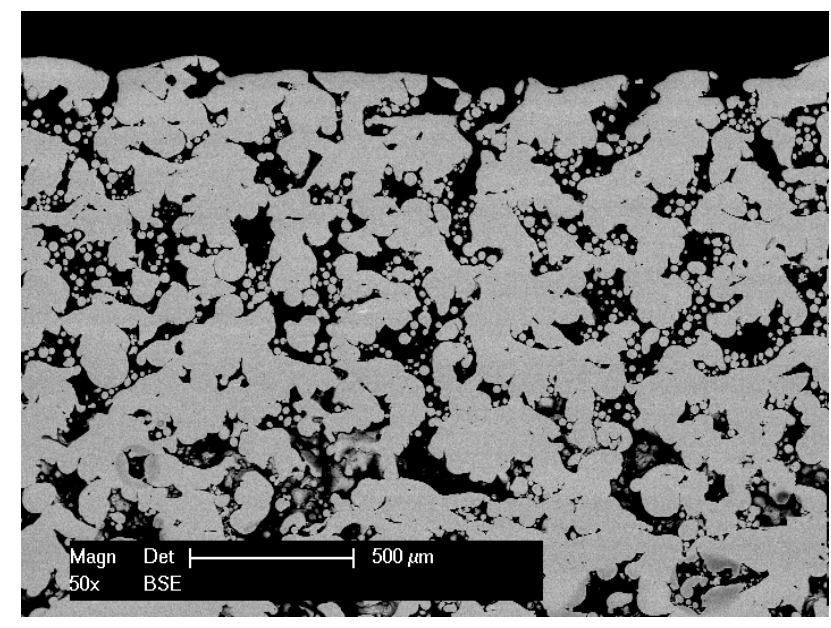

Fig.6 Example of cross-section SEM micrograph of the corroded 316L printed material

Figure 6 shows exemplary a SEM micrograph of the corroded SLM printed material in cross-section, which clearly reveals a near to homogeneous corrosion attack, with no evidence of pitting corrosion. Based on the nature of the void's interconnection, only after the first layer is completely corroded, the corrosion attack will start in the region of next layer. The generated corrosion products will assemble in such areas, depending on the surface roughness and will contribute to a partial inhibition of the corrosion reaction for a certain period.

\section{CONCLUSIONS}

In this study, the influence of $\mathrm{pH}$ and $\mathrm{DO}$ on the corrosion behaviour of forged and SLM printed 316L samples was investigated by testing the alloys in different $\mathrm{NaCl}$ solutions at room temperature. The results show that the forged $316 \mathrm{~L}$ material exhibited local corrosion attack (pitting), initiated in the regions with nonmetallic inclusions, while the $3 \mathrm{D}$ printed one displayed rather a generalized surface degradation.

Correlations of the polarisation curves of the tested SLM specimens, showed that the porosity and the presence of some oxides on the surface strongly influence the corrosion resistance. The higher porosity enhanced the degree of corrosion attack in neutral $\mathrm{NaCl}$ media. Contradictory observations concerning the corrosion resistance, respectively the stability of the passive film, were made in $\mathrm{NaCl}$ solution at $\mathrm{pH} 3.5$.

Supplementary work must be done by further optimization of the printing parameters in order to obtain samples with a reduced amount of small size voids. Moreover, the influence of further $\mathrm{pH}$ values on the corrosion mechanism of the printed sample has to be investigated.

\section{REFERENCES}

[1] Hertlein N, Deshpande S, Venugopal V, Kumar M, (2020) Anand S. Prediction of selective laser melting part quality using hybrid Bayesian network. Additive Manufacturing;32:101089.

https://doi.org/10.1016/j.addma.2020.101089.

[2] Riemer A, Leuders S, Thöne M, Richard HA, Tröster T, Niendorf T. (2014) On the fatigue crack growth behavior in $316 \mathrm{~L}$ stainless steel manufactured by selective laser melting. Engineering Fracture Mechanics;120:15-25. https://doi.org/10.1016/j.engfracmech.2014.03.008.

[3] Trosch T, Strößner J, Völkl R, Glatzel U. (2016) Microstructure and mechanical properties of selective laser melted Inconel 718 compared to forging and casting. Materials Letters;164:428-31. https://doi.org/10.1016/j.matlet.2015.10.136.

[4] Wang D, Yang Y, Liu R, Xiao D, Sun J. (2013) Study on the designing rules and processability of porous structure based on selective laser melting (SLM). Journal of Materials Processing Technology;213:1734-42.

https://doi.org/10.1016/j.jmatprotec.2013.05.001. 
[5] Yap CY, Chua CK, Dong ZL, Liu ZH, Zhang DQ, Loh LE, et al. (2015) Review of selective laser melting: Materials and applications. Applied Physics Reviews;2:041101.

https://doi.org/10.1063/1.4935926.

[6] Zygula K, Nosek B, Pasiwiec H, Szysiac N. (2018) Mechanical properties and microstructure of AlSi10Mg alloy obtained by casting and SLM technique. World Scientific News;104:462-72.

[7] Yin YJ, Sun JQ, Guo J, Kan XF, Yang DC. (2019) Mechanism of high yield strength and yield ratio of $316 \mathrm{~L}$ stainless steel by additive manufacturing. Materials Science and Engineering: A;744:773-7. https://doi.org/10.1016/j.msea.2018.12.092.

[8] Wang X, Carter LN, Pang B, Attallah MM, Loretto MH. (2017) Microstructure and yield strength of SLM-fabricated CM247LC Ni-Superalloy. Acta Materialia;128:87-95.

https://doi.org/10.1016/j.actamat.2017.02.007.

[9] Montero-Sistiaga M, Nardone S, Hautfenne C, Humbeeck J. (2016) Effect of heat treatment of 316L stainless steel produced by Selective Laser Melting (SLM). Proceedings of the 26th Annual International Solid Freeform Fabrication Symposium - An Additive Manufacturing Conference, Texas, USA.

[10] Laleh M, Hughes AE, Yang S, Li J, Xu W, Gibson I, et al. (2020) Two and three-dimensional characterisation of localised corrosion affected by lack-of-fusion pores in $316 \mathrm{~L}$ stainless steel produced by selective laser melting. Corrosion Science;165:108394.

https://doi.org/10.1016/j.corsci.2019.108394.

[11] Kale AB, Kim B-K, Kim D-I, Castle EG, Reece M, Choi S-H. (2020) An investigation of the corrosion behavior of 316L stainless steel fabricated by SLM and SPS techniques. Materials Characterization;163:110204.

https://doi.org/10.1016/j.matchar.2020.110204.

[12] Ni X, Kong D, Wu W, Zhang L, Dong C, He B, et al. (2018) Corrosion Behavior of 316L Stainless Steel Fabricated by Selective Laser Melting Under Different Scanning Speeds. Journal of Materials Engineering and Performance;27:3667-77. https://doi.org/10.1007/s11665-018-3446-z.

[13] Yadroitsev I, Gusarov A, Yadroitsava I, Smurov I. (2010) Single track formation in selective laser melting of metal powders. Journal of Materials Processing Technology;210:1624-31. https://doi.org/10.1016/j.jmatprotec.2010.05.010.

[14] Murkute P, Pasebani S, Isgor OB. (2019) Production of corrosion-resistant $316 \mathrm{~L}$ stainless steel clads on carbon steel using powder bed fusion-selective laser melting. Journal of Materials Processing Technology;273:116243.

https://doi.org/10.1016/j.jmatprotec.2019.05.024.

[15] Sabzi M, Dezfuli SM. (2018) Drastic improvement in mechanical properties and weldability of $316 \mathrm{~L}$ stainless steel weld joints by using electromagnetic vibration during GTAW process. Journal of Manufacturing Processes;33:74-85. https://doi.org/10.1016/j.jmapro.2018.05.002.

[16] Zhong Y, Liu L, Wikman S, Cui D, Shen Z. (2016) Intragranular cellular segregation network structure strengthening $316 \mathrm{~L}$ stainless steel prepared by selective laser melting. Journal of Nuclear Materials;470:170-8.

https://doi.org/10.1016/j.jnucmat.2015.12.034.

[17] Khalaf MK, Mazhir SN, Mahdi MS, Taha SK, Bououdina M. (2018) Influence of RF sputtering power on surface properties and biocompatibility of 316L stainless steel alloy by deposition of $\mathrm{TiO} 2$ thin films. Materials Research Express;6:035401. https://doi.org/10.1088/2053-1591/aaf2e9.

[18] Wang Z, Seyeux A, Zanna S, Maurice V, Marcus P. (2020) Chloride-induced alterations of the passive film on $316 \mathrm{~L}$ stainless steel and blocking effect of pre-passivation. Electrochimica Acta;329:135159. https://doi.org/10.1016/j.electacta.2019.135159.

[19] Wang Z, Di-Franco F, Seyeux A, Zanna S, Maurice V, Marcus P. (2019) Passivation-Induced Physicochemical Alterations of the Native Surface Oxide Film on 316L Austenitic Stainless Steel. Journal of The Electrochemical Society;166:C337688. https://doi.org/10.1149/2.0321911jes.

[20] Zhang Y, Liu F, Chen J, Yuan Y. (2017) Effects of surface quality on corrosion resistance of $316 \mathrm{~L}$ stainless steel parts manufactured via SLM. Journal of Laser Applications;29:022306. https://doi.org/10.2351/1.4983263.

[21] Luo H, Su H, Dong C, Li X. (2017) Passivation and electrochemical behavior of $316 \mathrm{~L}$ stainless steel in chlorinated simulated concrete pore solution. Applied Surface Science;400:38-48. https://doi.org/10.1016/j.apsusc.2016.12.180.

[22] Sun Y, Moroz A, Alrbaey K. (2014) Sliding Wear Characteristics and Corrosion Behaviour of Selective Laser Melted 316L Stainless Steel. Journal of Materials Engineering and Performance; 23:518-26. https://doi.org/10.1007/s11665-0130784-8.

[23] Sander G, Jiang D, Wu Y, Birbilis N. (2020) Exploring the possibility of a stainless steel and glass composite produced by additive manufacturing. Materials \& Design;196:109179. https://doi.org/10.1016/j.matdes.2020.109179. 


\section{NOTE}

This paper is based on the paper presented at 15th International Conference on Accomplishments in Mechanical and Industrial Engineering - DEMI 2021, organized by University of Banja Luka, Faculty of Mechanical Engineering, in Banja Luka, Bosnia \& Herzegovina, May 2021. 